\title{
BMJ Open Acute effects of air pollution on ischaemic stroke onset and deaths: a time-series study in Changzhou, China
}

\author{
Huibin Dong, ${ }^{1}$ Yongquan Yu, ${ }^{2}$ Shen Yao, ${ }^{2}$ Yan Lu, ${ }^{3}$ Zhiyong Chen, ${ }^{1}$ Guiying Li, \\ Yao Yao, ${ }^{1}$ Xingjuan Yao, ${ }^{1}$ Shou-Lin Wang, ${ }^{2}$ Zhan Zhang ${ }^{4}$
}

\begin{abstract}
To cite: Dong $\mathrm{H}, \mathrm{Yu} \mathrm{Y}$, Yao S, et al. Acute effects of air pollution on ischaemic stroke onset and deaths: a time-series study in Changzhou, China. BMJ Open 2018;8:e020425. doi:10.1136/ bmjopen-2017-020425

- Prepublication history and additional material for this paper are available online. To view these files, please visit the journal online (http://dx.doi. org/10.1136/bmjopen-2017020425).
\end{abstract}

$\mathrm{HD}$ and $\mathrm{YY}$ contributed equally.

Received 3 November 2017

Revised 10 May 2018

Accepted 5 June 2018

Check for updates

(c) Author(s) (or their employer(s)) 2018. Re-use permitted under CC BY-NC. No commercial re-use. See rights and permissions. Published by BMJ.

${ }^{1}$ Department of Chronic Disease Control and Prevention, Changzhou Center for Disease Control and Prevention, Changzhou, China

${ }^{2}$ Department of Occupational Medicine and Environmental Health, School of Public Health, Nanjing Medical University, Nanjing, China

${ }^{3}$ Department of Cardiology, The First Affiliated Hospital of Nanjing Medical University,

Nanjing, China

${ }^{4}$ Department of Hygiene Analysis and Detection, School of

Public Health, Nanjing Medical University, Nanjing, China

Correspondence to

Dr Zhan Zhang;

zhanzhang@njmu.edu.cn

\section{ABSTRACT}

Objective To investigate the acute effect of air pollutants on ischaemic stroke (IS) and IS-related death.

Setting Five urban districts in Changzhou, China, between 9 January 2015 and 31 December 2016.

Participants A total of 32840 IS cases and 4028 IS deaths were enrolled.

Main outcome measures A time-series design, generalised additive model and multivariable regression model were used to examine the percentage change (95\% $\mathrm{Cl}$ ) in daily IS counts and deaths with an IQR increase in air pollutant levels for different single or multiple lag days in single-pollutant and two-pollutant models.

Results Daily IS counts increased $0.208 \%(95 \% \mathrm{Cl}$ $0.036 \%$ to $0.381 \%$ ) with an IQR increment in the levels of nitrogen dioxide $\left(\mathrm{NO}_{2}\right)$. The estimated risk of $\mathrm{NO}_{2}$ was more robust in males and in the cold season. For daily IS counts, the estimated effects of $\mathrm{NO}_{2}$ and sulfur dioxide $\left(\mathrm{SO}_{2}\right)$ were more significant when adjusted for particulate matter with aerodynamic diameters $<2.5 \mu \mathrm{m}\left(\mathrm{PM}_{2.5}\right)$ and $\mathrm{PM}_{10}$. An IQR increment in the concentration of $\mathrm{PM}_{10}, \mathrm{SO}_{2}$ and $\mathrm{NO}_{2}$ significantly increased IS deaths with 6 days of cumulative effects $(0.268 \%, 95 \% \mathrm{Cl} 0.007 \%$ to $1.528 \%$; $0.34 \%$, $0.088 \%$ to $0.592 \%$; and $0.263 \%, 0.004 \%$ to $0.522 \%$, respectively). Young individuals ( $<65$ years old) had a higher IS mortality risk for $\mathrm{PM}_{25}, \mathrm{PM}_{10}, \mathrm{NO}_{2}$ and $\mathrm{CO}$. For IS death, the effect estimates of $\mathrm{SO}_{2}$ in the elderly, females and the cold season were more pronounced; statistical significance was also identified for $\mathrm{SO}_{2}$ when adjusted for carbon monoxide (CO).

Conclusions This study suggested that short-term exposure to ambient $\mathrm{NO}_{2}$ was associated with increased IS risk. In addition, $\mathrm{SO}_{2}$ was associated with increased IS onset and death.

\section{INTRODUCTION}

Air pollution is considered a primary risk factor for a mounting total of pollution-related diseases and deaths. ${ }^{1}$ Moreover, as a modifiable risk factor, air pollution accounts for more than 7 million deaths annually. ${ }^{2}$ Studies have extensively explored the association between air pollution and the risk of respiratory, reproductive and cardiovascular diseases. $^{3-5}$ Epidemiological studies have suggested that exposure to air pollutants on

\section{Strengths and limitations of this study}

- This is the first comprehensive research in China that explores the short-term effects of air pollutants on the morbidity and mortality of stroke concurrently.

- The statistical power to detect the association was sufficient because of the substantial numbers of ischaemic stroke (IS) cases and IS deaths recorded in our work.

- This time-series study evaluated the association of modifiers between air pollution and daily IS counts or deaths which may provide clues for the primary prevention of IS and IS-related death.

- The exposure measurement of this study was performed at the community level, and we could not precisely quantify the exposure of individuals to air pollutants using the fixed-site monitoring data; this may lead to exposure measurement error.

- This study considers a single city, and the results should be extrapolated with caution.

hazy days may increase the risk of cardiovascular diseases. ${ }^{6-8}$ For instance, a study conducted in Stockholm suggested that short-term exposure to particulate matter with aerodynamic diameters $<2.5 \mu \mathrm{m}\left(\mathrm{PM}_{2.5}\right)$ was associated with out-of-hospital cardiac arrest. Increments in $\mathrm{PM}_{2.5}, \mathrm{PM}_{10}$, nitrogen dioxide $\left(\mathrm{NO}_{2}\right)$, sulfur dioxide $\left(\mathrm{SO}_{2}\right)$ and carbon monoxide $(\mathrm{CO})$ were associated with higher risk of heart failure hospitalisations and death. A study conducted in Stockholm suggested that short-term exposure to $\mathrm{PM}_{2.5}$ was associated with out-of-hospital cardiac arrest. A meta-analysis indicated that longterm exposure to $\mathrm{PM}_{2.5}$ was related to a dramatic increase in cardiovascular mortality. ${ }^{9}$

Stroke is a persistent neurological deficit caused by cerebrovascular damage and includes ischaemic stroke (IS) and haemorrhagic stroke. ${ }^{10-12}$ Stroke is one of the leading causes of death and disability-adjusted life years worldwide. ${ }^{1314}$ In 2010 , the estimated number of individuals who suffered from stroke was 50 million, and among them, 
approximately 17 million cases were newly identified. China bears an enormous stroke burden in the world, having the highest stroke prevalence, incidence and mortality among low-income and middle-income countries worldwide. ${ }^{15}$ As the major subtype of stroke in China, IS accounts for $43 \%-79 \%$ of all strokes and has recently prompted growing concerns. ${ }^{16}$ Given the tremendous disease burden of stroke, the identification and prevention of risk factors are critical and effective public health strategies. ${ }^{17}$ However, the effect of air pollutants remains a matter of debate which might be, at least in part, explained by the heterogeneity of different stroke subtypes. ${ }^{18} 19$ Thus, there is a pressing need to systematically explore the association between air pollutants and specific subtypes of stroke-related incidence and mortality.

Changzhou stands on the southern bank of the Yangtze River. The city is part of the Suzhou-Wuxi-Changzhou metropolitan area, and by the year 2010 , there were approximately 4 million residents in five urban districts (Tianning district, Wujin district, Jintan district, Xinbei district and Liyang city).$^{20}$ Moreover, because of the rapid industrialisation and economic development of the past years, Changzhou is now experiencing severe air pollution. The concentrations of several air pollutants (such as $\mathrm{PM}_{25}, \mathrm{PM}_{10}, \mathrm{SO}_{2}$ and $\mathrm{NO}_{2}$ ) were equal or higher than the national ambient air quality in the recent years. ${ }^{21} 22$ Therefore, Changzhou was chosen as a suitable place to study the effect of air pollution on the incidence and mortality of IS. In this research, a comprehensive time-series study was conducted in Changzhou to examine the association between main air pollutants and daily IS counts and deaths. To explore the modification effect, the association of modifiers between air pollution and daily IS counts and deaths was also evaluated. This work will help provide insights into the relationship between stroke and air pollutants and have implications for the prevention of IS onset and IS-related deaths.

\section{MATERIALS AND METHODS \\ Data collection}

Air pollution data, including daily 24 hours average levels of $\mathrm{PM}_{2.5}, \mathrm{PM}_{10}, \mathrm{NO}_{2}, \mathrm{SO}_{2}$ and $\mathrm{CO}$ between 9 January 2015 and 31 December 2016, were obtained from 10 air quality monitoring stations run by the Changzhou Environmental Monitoring Center. The daily mean levels for air pollutants were averaged from all the stations, and approximately all the patients whose cases were recorded in this study resided less than $40 \mathrm{~km}$ from the nearest monitoring station. Thus, the monitoring data could be used as an appropriate proxy for personal exposure. ${ }^{23-25}$ Daily meteorological data on temperature $\left({ }^{\circ} \mathrm{C}\right)$ and relative humidity (\%) were collected from the Changzhou Meteorological Bureau.

Daily IS and IS mortality data from 9 January 2015 to 31 December 2016 were obtained from the database of the Changzhou Center for Disease Control and Prevention.
This database belonged to the government-controlled network reporting system for chronic diseases which was established in Changzhou in 2012. Cardiovascular physicians were responsible for the diagnosis of IS according to the cerebrovascular 10th revision of the International statistical classification of diseases (ICD-10) codes for IS (I63). Demographic data were collected from the Changzhou Municipal Bureau of Statistics. Daily IS counts and deaths were also stratified into groups by sex (male and female) and age group ( $<65$ and $\geq 65$ years) to explore the effect modification of individual characteristics.

\section{Statistical analysis}

Daily IS counts, daily IS death counts, air pollutant levels and weather data were linked by date for the subsequent time-series study which was used to analyse the effects of each air pollutant on IS counts and deaths. After evaluating the distribution patterns of daily IS counts and deaths, Poisson distributions were identified. Poisson regression was used in a generalised additive model to analyse the data. A multivariable regression model was used to detect the air pollutant-related associations and control for the potential confounding factors, such as calendar time, day of week (DOW), daily average relative humidity and temperature. The five $\mathrm{df}$ was used to adjust for all the confounding factors mentioned above except for DOW $(\mathrm{df}=7)$. Furthermore, to explore the potential modifications, data were stratified by sex, age ( $<65$ as young individuals and $\geq 65$ as elderly individuals) and season (warm season as 1 May to 31 October and cold season as 1 November to 30 April). Associations between air pollutants and IS and IS-related deaths were separately examined according to the following equation:

$$
\begin{aligned}
& \log \left[E\left(T / D_{n}\right)\right]=\text { intercept }+\beta_{1} \text { AirPollution }_{n-i}+\beta_{2} D O W \\
& +p s\left(\text { calendartime, } d f=7+p s\left(\text { Temp }_{n-i}, d f=5\right)\right. \\
& +p s\left(\text { RelativeHumidity } y_{n-i}, d f=5\right)
\end{aligned}
$$

$\mathrm{E}\left(\mathrm{T} / \mathrm{D}_{\mathrm{n}}\right)$ represents the estimated numbers of IS onset or death on day n; AirPollution ${ }_{n-i}$ represents the average level of different air pollutants on day $\mathrm{n}$ and $\mathrm{i}$ is the day lag; $\beta$ is the vector of the coefficients; DOW is the day of week; ps () represents a penalised spline function; Temp $p_{n-i}$ and Relative Humidity ${ }_{\mathrm{n}-\mathrm{i}}$ represent average temperature and relative humidity on day $\mathrm{n}$ and $\mathrm{i}$ is the day lag.

In addition, for both daily IS counts and deaths, single-pollutant models were fitted with different single-lag days ( $\operatorname{lag} 0$, lag 1 , lag 3 and lag 5) to detect the effects of air pollution on IS. As underestimation may occur in single-day models, multiple-day lag models (lag 0-1, lag 0-3 and lag 0-5) were also applied in this study. The smoothing function was used in the analysis of the exposure-response relationship between the log-relative risk of daily IS counts or deaths and air pollutant concentrations using a five $\mathrm{df}$ in a single-pollutant model. 
Statistical software R V.3.2.3 (R Foundation for Statistical Computing, Austria) was used for data analysis and result output. The baseline data was presented as the mean $\pm \mathrm{SD}$ for continuous variables. All tests were two-sided, and $\mathrm{p}<0.05$ was considered as statistically significant.

\section{Public and patient involvement}

Public and patient involvement (PPI) was central and integral in the present study. The PPI group consisted of three male and four female representative patients who were recruited and chaired by HD. The members of the existing group were involved throughout all stages of this research to make contributions. At the outset, they helped researchers with choosing topics and designing the study by providing constructive suggestions. Furthermore, they took part in the conference presentations and group discussions to help filter and interpret data collected from the database mentioned above. They also contributed to discussions about the implications of the results by drawing on their experiences. Findings were disseminated to all PPI members at the end of the study.

\section{RESULTS}

\section{Descriptive analysis}

During this study period, there were 32840 IS cases and 4028 IS deaths recorded. For IS, on average, 45.4 cases were identified each day (online supplementary table S1). Of these, $52.2 \%$ were males and $81.3 \%$ were the elderly $(\geq 65)$. In addition, for IS-related death, there were 5.6 deaths recorded on average each day (online supplementary table $\mathrm{S} 1$ ). Of these, $48.2 \%$ were males and $96.4 \%$ were the elderly.

The daily average meteorological data were $17.0^{\circ} \mathrm{C}$ for temperature and $75 \%$ for relative humidity. The daily average levels were $51.8 \mu \mathrm{g} / \mathrm{m}^{3}$ for $\mathrm{PM}_{25}, 85.3 \mu \mathrm{g} / \mathrm{m}^{3}$ for $\mathrm{PM}_{10}, 22.3 \mu \mathrm{g} / \mathrm{m}^{3}$ for $\mathrm{SO}_{2}, 38.7 \mu \mathrm{g} / \mathrm{m}^{3}$ for $\mathrm{NO}_{2}$ and $1 \mathrm{mg} /$ $\mathrm{m}^{3}$ for $\mathrm{CO}$ (table 1 ). According to $\mathrm{WHO}$, air quality guidelines $\left(25 \mu \mathrm{g} / \mathrm{m}^{3}\right.$ for $\mathrm{PM}_{2.5}, 50 \mu \mathrm{g} / \mathrm{m}^{3}$ for $\mathrm{PM}_{10}$ and $20 \mu \mathrm{g} /$ $\mathrm{m}^{3}$ for $\mathrm{SO}_{2}$ ), the corresponding average levels of $\mathrm{PM}_{2.5}$,
$\mathrm{PM}_{10}$ and $\mathrm{SO}_{2}$ in Changzhou were far beyond the WHO standard.

\section{Estimated effects of air pollutants}

Figure 1 summarises the percentage change (95\% CI) in daily IS counts and deaths with an IQR increase in air pollutant levels for different single-lag or multiple-lag days in single-pollutant models. For daily IS counts, a statistically positive association was observed only for an IQR increment of $\mathrm{NO}_{2}$ levels, and this association was more significant for multi-day exposure than for single-day exposure. The highest association was observed for lag $0-5(0.208 \%, 0.036 \%$ to $0.381 \%)$ and was used in the subsequent study. For daily IS deaths, statistically positive associations were observed for the different IQRs increments of $\mathrm{PM}_{10}, \mathrm{SO}_{2}$ and $\mathrm{NO}_{2}$. All associations were the most significant at lag $5(0.268 \%$, $0.007 \%$ to $0.528 \%$ for $\mathrm{PM}_{10} ; 0.34 \%, 0.088 \%$ to $0.592 \%$ for $\mathrm{SO}_{2}$; and $0.263 \%, 0.004 \%$ to $0.522 \%$ for $\mathrm{NO}_{2}$ ) than at other days and thus a 5-day lag model was used in the subsequent analysis.

Concentration-response relationships of air pollutants with daily IS counts or deaths are presented in figure 2. For IS counts, the curve of $\mathrm{NO}_{2}$ was linear positive and flat at higher concentrations. For daily IS deaths, the concentration-response curves of $\mathrm{PM}_{10}$ and $\mathrm{SO}_{2}$ were similar, that is, flat at low levels and dramatically linear positive at high levels, whereas the curve for $\mathrm{NO}_{2}$ suggest a linear rise in daily IS deaths.

The effect of $\mathrm{NO}_{2}$ on the increase of daily IS counts was more pronounced among males than among females, and the effects of $\mathrm{NO}_{2}$ and $\mathrm{SO}_{2}$ on daily IS counts were stronger in the cold season than in the warm season. No significant association was observed when modifying by age (table 2). For daily IS deaths, the estimated effect of $\mathrm{PM}_{10}$ was more pronounced among males, whereas the effects of $\mathrm{NO}_{2}$ and $\mathrm{SO}_{2}$ were more robust among females. Moreover, $\mathrm{PM}_{2.5}, \mathrm{PM}_{10}, \mathrm{NO}_{2}$ and $\mathrm{CO}$ were found to have greater deleterious effects among young individuals, and $\mathrm{SO}_{2}$ showed greater risk in the elderly. In addition, when

Table 1 The means, medians and IQRs for daily air pollutants and weather conditions variables in Changzhou, 2015-2016

\begin{tabular}{llrrrrrr}
\hline Variables & Mean \pm SD & Min & 25th & Median & 75th & Max & IQR \\
\hline $\begin{array}{l}\text { Weather Condition } \\
\quad \text { Temperature }\left({ }^{\circ} \mathrm{C}\right)\end{array}$ & $17.1 \pm 8.9$ & -6.6 & 9.4 & 18.3 & 24.1 & 34.6 & 5.8 \\
$\quad$ Humidity $(\%)$ & $75.3 \pm 14.2$ & 35.0 & 66.0 & 76.0 & 86.0 & 100.0 & 10.0 \\
Air Pollutions & & & & & & & \\
$\mathrm{PM}_{2.5}\left(\mu \mathrm{g} / \mathrm{m}^{3}\right)$ & $51.8 \pm 30.6$ & 6.8 & 29.4 & 44.4 & 64.4 & 181.1 & 20.0 \\
$\mathrm{PM}_{10}\left(\mu \mathrm{g} / \mathrm{m}^{3}\right)$ & $85.3 \pm 43.3$ & 10.5 & 51.5 & 76.6 & 108.6 & 289.1 & 32.0 \\
$\mathrm{NO}_{2}\left(\mu \mathrm{g} / \mathrm{m}^{3}\right)$ & $38.7 \pm 16$ & 10.9 & 26.5 & 35.8 & 47.8 & 117.3 & 12.0 \\
$\mathrm{SO}_{2}\left(\mu \mathrm{g} / \mathrm{m}^{3}\right)$ & $22.3 \pm 10$ & 6.9 & 14.7 & 20.2 & 27.0 & 67.8 & 6.9 \\
$\mathrm{CO}\left(\mathrm{mg} / \mathrm{m}^{3}\right)$ & $1 \pm 0.3$ & 0.4 & 0.8 & 1.0 & 1.2 & 2.6 & 0.2 \\
\hline
\end{tabular}

$\mathrm{CO}$, carbon monoxide; $\mathrm{NO}_{2}$, nitrogen dioxide; $\mathrm{PM}_{2.5}$, particulate matter $<2.5 \mu \mathrm{m}$ in diameter; $\mathrm{PM}_{10}$, particulate matter $<10 \mu \mathrm{m}$ in diameter; $\mathrm{SO}$, sulfur dioxide. 

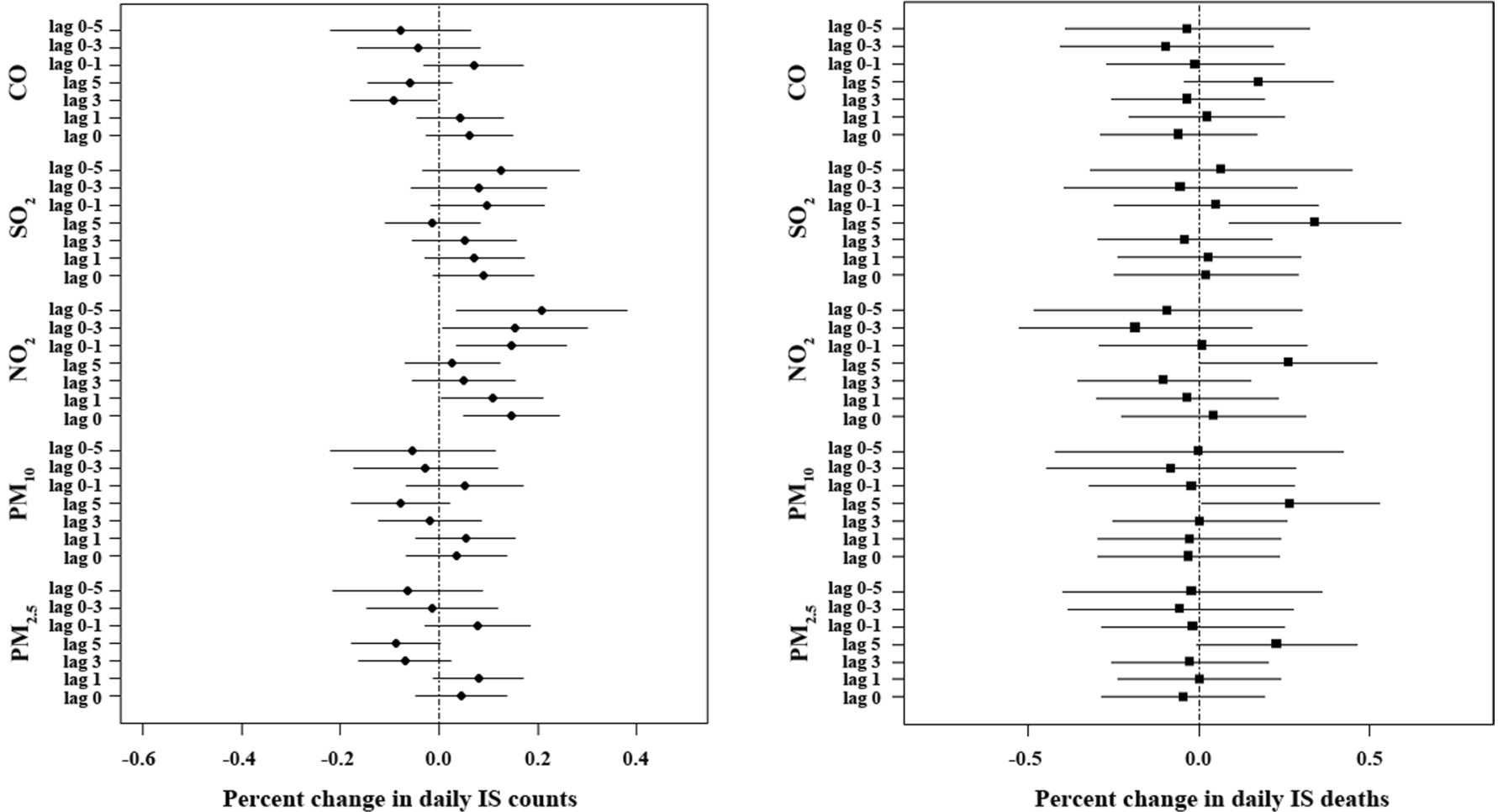

Figure 1 The percentage change in daily IS counts and daily IS deaths with an IQR increase in air pollutant levels on different lag days in single-pollutant models in Changzhou, 2015-2016. The data are expressed as the mean with a 95\% Cl. CO, carbon monoxide; IS, ischaemic stroke; $\mathrm{NO}_{2}$, nitrogen dioxide; $\mathrm{PM}_{2.5}$, particulate matter $<2.5 \mu \mathrm{m}$ in diameter; $\mathrm{PM}_{10}$, particulate matter $<10 \mu \mathrm{m}$ in diameter; $\mathrm{SO}_{2}$, sulfur dioxide.

modifying by seasons, statistical significance was noted only for $\mathrm{SO}_{2}$ in the cold season (table 2).

Table 3 shows the percentage increases in daily IS counts and daily IS deaths with each IQR increment in air pollutant levels in the two-pollutant models. For daily IS counts, the estimated effects of $\mathrm{NO}_{2}$ and $\mathrm{SO}_{2}$ were more serious when adjusted for $\mathrm{PM}_{2.5}$ and $\mathrm{PM}_{10}$. For daily IS deaths, statistical significance was identified for $\mathrm{SO}_{2}$ when adjusted for CO.

\section{DISCUSSION}

In this population-based time-series study, a total of 32840 IS cases and 4028 IS deaths were identified in Changzhou from 2015 to 2016. A significant association of $\mathrm{NO}_{2}$ with daily IS counts was observed even when adjusted by $\mathrm{PM}_{2.5}$ and $\mathrm{PM}_{10}$. The estimated IS risk of $\mathrm{NO}_{2}$ was more robust in the elderly and in the cold season. In addition, $\mathrm{PM}_{10}, \mathrm{SO}_{2}$ and $\mathrm{NO}_{2}$ were positively associated with daily IS deaths. Young individuals had a higher IS mortality risk for $\mathrm{PM}_{2.5}, \mathrm{PM}_{10}, \mathrm{NO}_{2}$ and $\mathrm{CO}$. In addition, the IS mortality risk of $\mathrm{SO}_{2}$ was more robust in the elderly, females and cold season; statistical significance was also identified for $\mathrm{SO}_{2}$ when adjusted for $\mathrm{CO}$. To the best of our knowledge, in China, this is the first comprehensive study to explore the acute effect of air pollutants on the morbidity and mortality of stroke concurrently.

$\mathrm{PM}_{10}$ can cause endothelial dysfunction, inflammatory response and neurofunctional impairment and, subsequently, induce ischaemia-like injuries in the brain. ${ }^{26}$ In the current study, an IQR increment in $\mathrm{PM}_{10}$ concentrations was associated with a $0.268 \%$ increment in daily IS deaths which was consistent with previous investigations. ${ }^{27} 28$ Moreover, the function curve for $\mathrm{PM}_{10} /$ daily IS deaths was flat at $<150 \mu \mathrm{g} / \mathrm{m}^{3}$ and became dramatically sharp at high levels. A previous multicity time-series study indicated an acute, deleterious and significant effect of $\mathrm{PM}_{10}$ on IS mortality, and the estimated rate ratio was 1.016. ${ }^{29}$ Long-term exposure to $\mathrm{PM}_{10}$ was positively associated with IS-relate death and the estimated relative risk was $1.37 .{ }^{30}$ Moreover, in this study, a greater estimated IS mortality risk was observed among males and young individuals. It is plausible that males and young people spent more time outdoors and were exposed to higher levels of $\mathrm{PM}_{10}$ than females and the elderly. ${ }^{31}$

$\mathrm{NO}_{2}$, a representative pollutant of vehicle exhaust, has been found to induce excitotoxicity and endothelial and inflammatory responses and to damage synaptic plasticity in the brain. ${ }^{32-34}$ In China, a multicity case-crossover study demonstrated that an IQR increase $\left(25.4 \mu \mathrm{g} / \mathrm{m}^{3}\right)$ in $\mathrm{NO}_{2}$ corresponded to a $2.6 \%$ increment in IS emissions. Stroke mortality was also positively associated with ambient $\mathrm{NO}_{2}$ levels. ${ }^{35}$ In the present study, we indicated that IQR increments in $\mathrm{NO}_{2}\left(12 \mu \mathrm{g} / \mathrm{m}^{3}\right)$ were associated with $0.208 \%$ and $0.263 \%$ increases in daily IS counts and IS deaths, respectively. An approximately linear concentrationresponse relationship was identified for $\mathrm{NO}_{2}$ and daily IS 

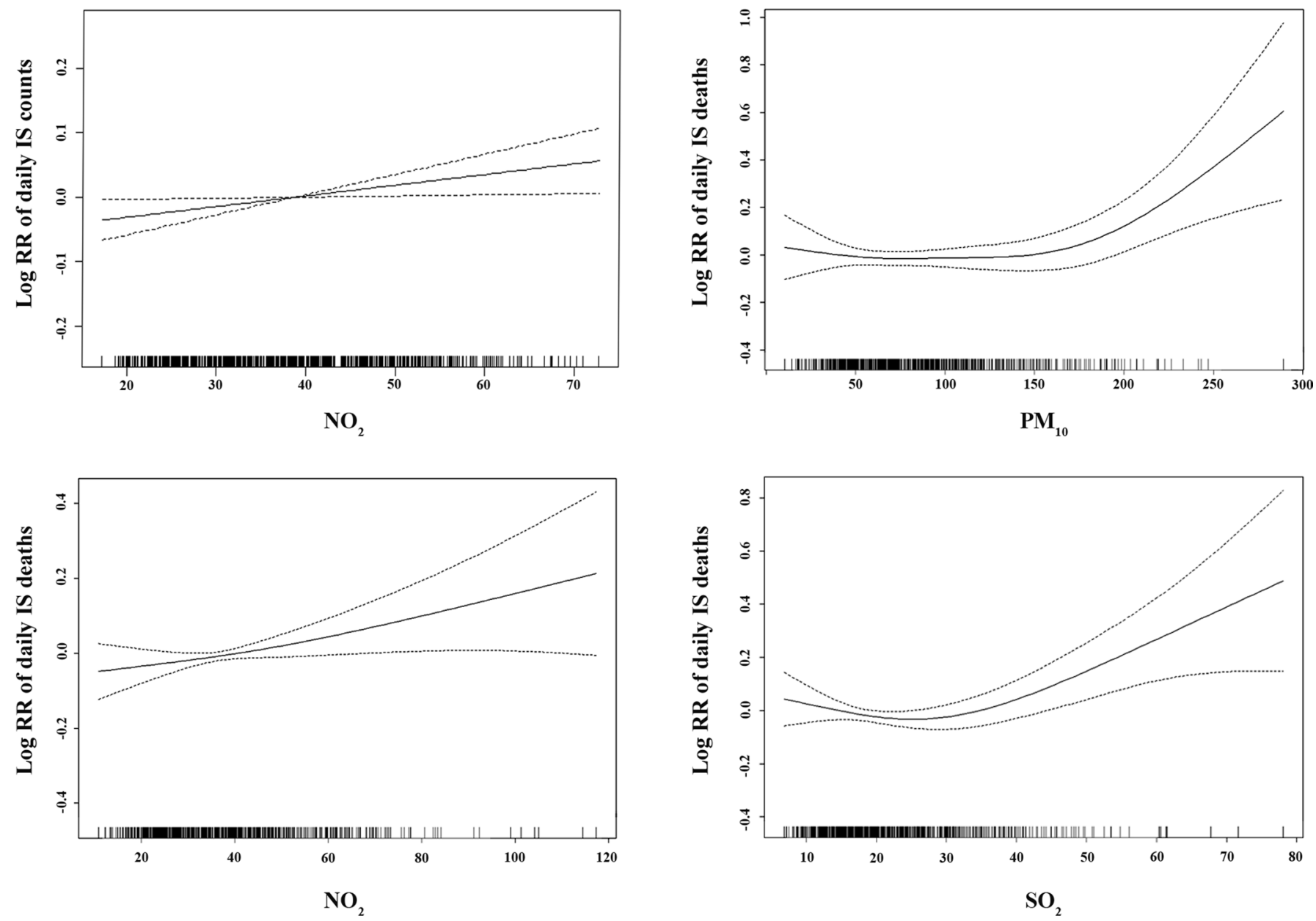

Figure 2 The concentration-response relationships of daily IS counts, daily IS deaths with air pollutants on different lag days (lag 0-5 for daily IS counts and lag 5 for daily IS deaths) in single-pollutant models in Changzhou, 2015-2016. IS, ischaemic stroke; $\mathrm{NO}_{2}$, nitrogen dioxide; $\mathrm{PM}_{10}$, particulate matter $<10 \mu \mathrm{m}$ in diameter; $\mathrm{RR}$, risk ratio; $\mathrm{SO}_{2}$, sulfur dioxide.

counts or daily IS deaths which was consistent with the previous studies. ${ }^{3637}$ The positive association for $\mathrm{NO}_{2}$ and daily IS counts could be observed even below the National Ambient Air Quality Standards of China $\left(80 \mu \mathrm{g} / \mathrm{m}^{3}\right)$. For daily IS counts, the effects of $\mathrm{NO}_{2}$ were statistically positive and stronger when adjusted for other pollutants, except for $\mathrm{SO}_{2}$ (no statistical association was detected, but a stronger association was observed), suggesting that the adverse effect of $\mathrm{NO}_{2}$ on IS onset was stable and that $\mathrm{NO}_{2}$ contributed most to the increased risk of IS. Moreover, the effects of $\mathrm{NO}_{2}$ were more serious in the cold season and in males. For IS deaths, young females were found to experience higher risk. An underlying reason may be that the exposure levels of $\mathrm{NO}_{2}$ were much higher at these conditions which was similar to that of $\mathrm{PM}_{10}$. The risk factors for stroke, such as hypertension, atrial fibrillation and diabetes mellitus are more frequent, and the estimated effects are stronger among females. ${ }^{38}$ Females are considered to be more sensitive to stroke onset and deaths. Thus, our findings regarding the higher risk of IS deaths observed among females were reasonable.

$\mathrm{SO}_{2}$ was considered a strong ambient, gaseous pollutant and irritant that could elevate the expression of vasoregulatory pathways and proinflammatory enzymes such as
ET-1, iNOS, COX-2, ICAM-1 and TNF- $\alpha .{ }^{39}$ In addition, exposure to it was demonstrated to contribute to the development and progression of IS. ${ }^{18}$ In the present study, $\mathrm{SO}_{2}$ was significantly associated with daily IS counts when adjusted by $\mathrm{PM}_{2.5}$ or $\mathrm{PM}_{10}$. In addition, exposure to $\mathrm{SO}_{2}$ also had statistical associations with daily IS deaths (the percentage increase was $0.34 \%$ ) which agreed with previous studies. ${ }^{1940}$ The function curve for $\mathrm{SO}_{2}$ and daily IS deaths was flat at $<35 \mu \mathrm{g} / \mathrm{m}^{3}$ and became dramatically sharp at high levels, suggesting that acute and robust increments of $\mathrm{SO}_{2}$ might exacerbate IS deaths. Furthermore, the associations were more pronounced among females, suggesting that females are more susceptible to IS-related deaths when exposed to gaseous pollutants $\left(\mathrm{NO}_{2}\right.$ and $\left.\mathrm{SO}_{2}\right)$. In addition, $\mathrm{SO}_{2}$ exhibited a higher risk of IS deaths in the elderly. ${ }^{41}$ Thus, it can be deduced that the elderly are more likely to have pre-existing respiratory or cardiovascular burdens, and these vulnerable conditions could influence the effect of $\mathrm{SO}_{2}$ on stroke. ${ }^{42}$ We also found that exposure to $\mathrm{SO}_{2}$ had more serious effects on both IS onset and deaths in the cold season than in the warm season. 


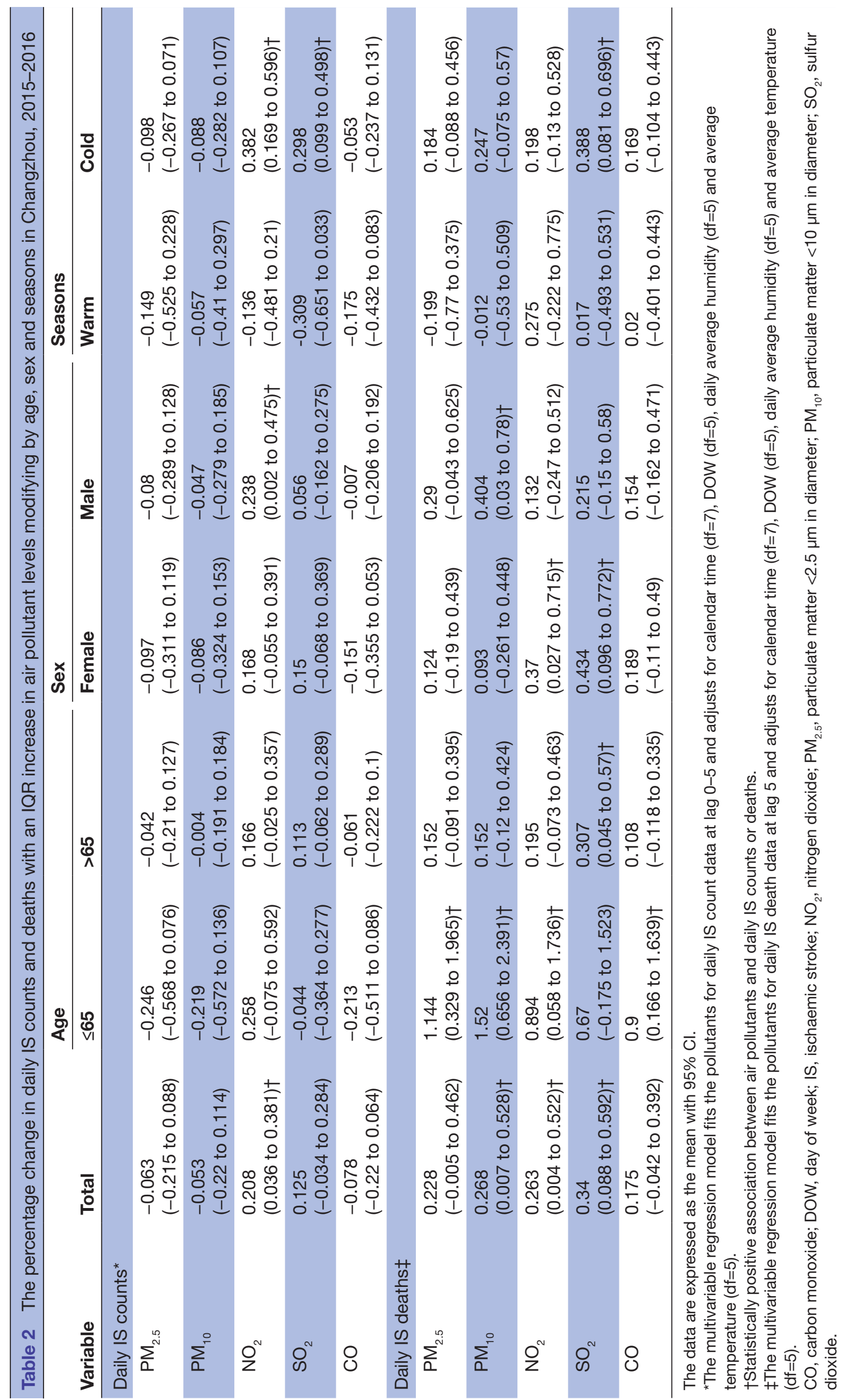


Table 3 The per cent increases in daily IS counts and deaths with each IQR increment in air pollutant levels in two-pollutant models in Changzhou, 2015-2016

\begin{tabular}{|c|c|c|c|c|c|}
\hline Variable & $\mathbf{P M}_{2.5}$ & $\mathbf{P M}_{10}$ & $\mathrm{NO}_{2}$ & $\mathrm{SO}_{2}$ & $\mathrm{CO}$ \\
\hline \multicolumn{6}{|c|}{ Daily IS counts* } \\
\hline $\mathrm{PM}_{2.5}$ & $\begin{array}{l}-0.063 \\
(-0.215 \text { to } 0.088)\end{array}$ & $\begin{array}{l}0.25 \\
(-0.314 \text { to } 0.817)\end{array}$ & $\begin{array}{l}0.497 \\
(0.259 \text { to } 0.735) \dagger\end{array}$ & $\begin{array}{l}0.305 \\
(0.083 \text { to } 0.527) \dagger\end{array}$ & $\begin{array}{l}-0.059 \\
(-0.274 \text { to } 0.157)\end{array}$ \\
\hline $\mathrm{PM}_{10}$ & $\begin{array}{l}-0.423 \\
(-0.881 \text { to } 0.038)\end{array}$ & $\begin{array}{l}-0.053 \\
(-0.22 \text { to } 0.114)\end{array}$ & $\begin{array}{l}0.539 \\
(0.29 \text { to } 0.788) \dagger\end{array}$ & $\begin{array}{l}0.262 \\
(0.034 \text { to } 0.491) \dagger\end{array}$ & $\begin{array}{l}-0.065 \\
(-0.293 \text { to } 0.163)\end{array}$ \\
\hline $\mathrm{SO}_{2}$ & $\begin{array}{l}-0.24 \\
(-0.46 \text { to } 0.019)\end{array}$ & $\begin{array}{l}-0.244 \\
(-0.49 \text { to } 0.003)\end{array}$ & $\begin{array}{l}0.22 \\
(-0.067 \text { to } 0.507)\end{array}$ & $\begin{array}{l}0.125 \\
(-0.034 \text { to } 0.284)\end{array}$ & $\begin{array}{l}-0.166 \\
(-0.356 \text { to } 0.023)\end{array}$ \\
\hline $\mathrm{CO}$ & $\begin{array}{l}-0.089 \\
(-0.314 \text { to } 0.137)\end{array}$ & $\begin{array}{l}0.029 \\
(-0.223 \text { to } 0.281)\end{array}$ & $\begin{array}{l}0.45 \\
(0.215 \text { to } 0.685) \dagger\end{array}$ & $\begin{array}{l}0.172 \\
(-0.016 \text { to } 0.361)\end{array}$ & $\begin{array}{l}-0.078 \\
(-0.22 \text { to } 0.064)\end{array}$ \\
\hline \multicolumn{6}{|c|}{ Daily IS deaths $\ddagger$} \\
\hline $\mathrm{NO}_{2}$ & $\begin{array}{l}0.106 \\
(-0.201 \text { to } 0.414)\end{array}$ & $\begin{array}{l}0.149 \\
(-0.21 \text { to } 0.509)\end{array}$ & $\begin{array}{l}0.263 \\
(0.004 \text { to } 0.522) \dagger\end{array}$ & $\begin{array}{l}0.351 \\
(-0.096 \text { to } 0.8)\end{array}$ & $\begin{array}{l}0.057 \\
(-0.269 \text { to } 0.384)\end{array}$ \\
\hline $\mathrm{SO}_{2}$ & $\begin{array}{l}0.066 \\
(-0.25 \text { to } 0.383)\end{array}$ & $\begin{array}{l}0.126 \\
(-0.242 \text { to } 0.496)\end{array}$ & $\begin{array}{l}0.066 \\
(-0.387 \text { to } 0.521)\end{array}$ & $\begin{array}{l}0.34 \\
(0.088 \text { to } 0.592) \dagger\end{array}$ & $\begin{array}{l}0.035 \\
(-0.281 \text { to } 0.351)\end{array}$ \\
\hline $\mathrm{CO}$ & $\begin{array}{l}0.186 \\
(-0.199 \text { to } 0.571)\end{array}$ & $\begin{array}{l}0.233 \\
(-0.187 \text { to } 0.656)\end{array}$ & $\begin{array}{l}0.23 \\
(-0.14 \text { to } 0.601)\end{array}$ & $\begin{array}{l}0.346 \\
(0.002 \text { to } 0.691) \dagger\end{array}$ & $\begin{array}{l}0.175 \\
(-0.042 \text { to } 0.392)\end{array}$ \\
\hline
\end{tabular}

The data are expressed as the mean with $95 \% \mathrm{Cl}$.

*The multivariable regression model fits the pollutants for daily IS counts data at lag 0-5 and adjusts for the other pollutants, calendar time $(\mathrm{df}=7)$, DOW $(\mathrm{df}=5)$, daily average humidity $(\mathrm{df}=5)$ and average temperature $(\mathrm{df}=5)$.

†Statistically positive association between air pollutants and daily IS counts or deaths.

$\ddagger$ The multivariable regression model fits the pollutants for daily IS deaths data at lag 5 and adjusts for the other pollutants, calendar time $(\mathrm{df}=7)$, DOW $(\mathrm{df}=5)$, daily average humidity $(\mathrm{df}=5)$ and average temperature $(\mathrm{df}=5)$.

$\mathrm{CO}$, carbon monoxide; DOW, day of week; IS, ischaemic stroke; $\mathrm{NO}_{2}$, nitrogen dioxide; $\mathrm{PM}_{2.5}$, particulate matter $<2.5 \mu \mathrm{m}$ in diameter; $\mathrm{PM}$, particulate matter $<10 \mu \mathrm{m}$ in diameter; $\mathrm{SO}_{2}$, sulfur dioxide.

Examining the deleterious effect of air pollutants on the incidence and outcomes of stroke is of significance, and previous studies mainly have focused on one aspect of IS in China. This study is one of the first to comprehensively explore the relationship between air pollutant levels and morbidity or mortality of IS. As numerous individuals were included to explore the associations, the results of this work strongly support the conclusion and may help provide insights into the relationship between air pollutants and IS. Furthermore, due to the severe air pollution and enormous stroke burden that Changzhou is now experiencing, the findings of this study may provide clues for the primary prevention of the onset or death related to IS, especially for sensitive populations. However, limitations should be noted in this study. Because individuals were identified retrospectively and not all hospitals were included, diagnostic errors and selection bias may exist. We relied on routine measurements from 10 fixed-site monitoring stations instead of more accurate measurement based on the individuals' residence and indoor exposure. Thus, we were not able to quantify the exposure of individuals precisely. Moreover, the data regarding IS cases and air pollutant levels were collected from only one city, and it is difficult to extrapolate the results to other areas in China. Further national or multicity studies are required.

In conclusion, our results suggested that short-term exposure to ambient $\mathrm{NO}_{2}$ was associated with increased IS risk. In addition, $\mathrm{SO}_{2}$ was associated with increased IS counts and deaths. These findings may have significant public health implications for the prevention of IS and IS-related deaths. Further studies are recommended to validate our research.

Acknowledgements The authors are grateful to the PPI group chaired by HD, who supported the wider programme of work of which the qualitative interviews are a part. The authors are also grateful to the patient representative and to other members of the study advisory group.

Contributors The study was conceived and designed by $\mathrm{HD}, \mathrm{YL}$ and $\mathrm{ZZ}$, and overall study management was by XY, S-LW and ZZ. ZC, GL and YYao contributed to data collection and processing. SY performed the statistical analysis. HD, YYu and $Y L$ helped in manuscript preparation and interpretation of the results. All authors contributed to the revision of the manuscript and reviewed and approved the final version. 
Funding This work was supported by the Natural Science Foundation of China (81502801), a project funded by the Priority Academic Program Development of Jiangsu Higher Education Institutions (2014), a collegiate Natural Science Foundations of Jiangsu province (16KJB330005), the science and technology support programme funded by Changzhou Municipal Science and Technology Bureau (CE20145046) and the Science and Technique Foundation for Youths by Health and Family Planning Commission of Changzhou (QN201603).

Disclaimer The funding sponsors had no role in the design of the study, in the collection, analysis or interpretation of data, in the writing of the manuscript or in the decision to publish the research results.

Competing interests None declared.

Patient consent Not required.

Ethics approval The present study was approved by the Institutional Review Board of the Changzhou Center for Disease Control and Prevention, and all procedures were in accordance with prevailing ethical principles.

Provenance and peer review Not commissioned; externally peer reviewed. Data sharing statement № additional data are available.

Open access This is an open access article distributed in accordance with the Creative Commons Attribution Non Commercial (CC BY-NC 4.0) license, which permits others to distribute, remix, adapt, build upon this work non-commercially, and license their derivative works on different terms, provided the original work is properly cited, appropriate credit is given, any changes made indicated, and the use is non-commercial. See: http://creativecommons.org/licenses/by-nc/4.0/.

\section{REFERENCES}

1. World Health Organization. 7 million premature deaths annually linked to air pollution. Air Quality \& Climate Change 2014 http://www. who.int/mediacentre/news/releases/2014/air-pollution/en/.

2. Vijayan VK, Paramesh H, Salvi SS, et al. Enhancing indoor air quality -The air filter advantage. Lung India 2015;32:473-9.

3. Radwan M, Jurewicz J, Polańska K, et al. Exposure to ambient air pollution--does it affect semen quality and the level of reproductive hormones? Ann Hum Biol 2016;43:50-6.

4. Mills NL, Donaldson K, Hadoke PW, et al. Adverse cardiovascular effects of air pollution. Nat Clin Pract Cardiovasc Med 2009;6:36-44.

5. Bayram H, Dikensoy $\mathrm{O}$. Effects of air pollution on respiratory health. Int J Mycobacteriol 2015;4:59.

6. Raza A, Bellander T, Bero-Bedada G, et al. Short-term effects of air pollution on out-of-hospital cardiac arrest in Stockholm. Eur Heart J 2014:35:861-8.

7. Shah AS, Langrish JP, Nair $\mathrm{H}$, et al. Global association of air pollution and heart failure: a systematic review and meta-analysis. Lancet 2013;382:1039-48.

8. Hoek G, Krishnan RM, Beelen R, et al. Long-term air pollution exposure and cardio- respiratory mortality: a review. Environ Health 2013;12:43.

9. Atkinson RW, Kang S, Anderson HR, et al. Epidemiological time series studies of $\mathrm{PM}_{25}$ and daily mortality and hospital admissions: a systematic review and meta-analysis. Thorax 2014;69:660-5.

10. World Health Organization. Cerebrovascular Disorders: A Clinical and Research Classification, 1978. ISBN 10: 9241700432 ISBN 13: 9789241700436.

11. Guiraud V, Amor MB, Mas JL, et al. Triggers of ischemic stroke: a systematic review. Stroke 2010;41:2669-77.

12. Ohira T, Shahar E, Chambless LE, et al. Risk factors for ischemic stroke subtypes: the Atherosclerosis Risk in Communities study. Stroke 2006;37:2493-8.

13. Lozano R, Naghavi M, Foreman $\mathrm{K}$, et al. Global and regional mortality from 235 causes of death for 20 age groups in 1990 and 2010: a systematic analysis for the Global Burden of Disease Study 2010. Lancet 2012;380:2095-128.

14. Murray CJ, Vos T, Lozano R, et al. Disability-adjusted life years (DALYs) for 291 diseases and injuries in 21 regions, 1990-2010: a systematic analysis for the Global Burden of Disease Study 2010. Lancet 2012;380:2197-223.

15. Wang W, Jiang B, Sun $\mathrm{H}$, et al. Prevalence, Incidence, and Mortality of Stroke in China: Results from a Nationwide Population-Based Survey of 480687 Adults. Circulation 2017;135:759-71.
16. Liu L, Wang D, Wong KS, et al. Stroke and stroke care in China: huge burden, significant workload, and a national priority. Stroke 2011;42:3651-4.

17. Straus SE, Majumdar SR, McAlister FA. New evidence for stroke prevention: scientific review. JAMA 2002;288:1388-95.

18. Chung JW, Bang OY, Ahn K, et al. Air Pollution Is Associated With Ischemic Stroke via Cardiogenic Embolism. Stroke 2017;48:17-23.

19. Yang WS, Wang X, Deng Q, et al. An evidence-based appraisal of global association between air pollution and risk of stroke. Int $J$ Cardiol 2014;175:307-13.

20. Kerstens SM, de Mes TZ, Lue B. Designing sustainable sanitation in urban planning proposed for Changzhou, China. Water Sci Technol 2009;60:3165-72.

21. Li L, Chen $\mathrm{CH}$, Huang $\mathrm{C}$, et al. [Regional air pollution characteristics simulation of $\mathrm{O} 3$ and PM10 over Yangtze River Delta region]. Huan Jing Ke Xue 2008;29:237-45.

22. Liao Z, Gao M, Sun J, et al. The impact of synoptic circulation on air quality and pollution-related human health in the Yangtze River Delta region. Sci Total Environ 2017;607-608:838-46.

23. Dockery DW, Luttmann-Gibson $\mathrm{H}$, Rich $\mathrm{DQ}$, et al. Association of air pollution with increased incidence of ventricular tachyarrhythmias recorded by implanted cardioverter defibrillators. Environ Health Perspect 2005;113:670-4.

24. Wellenius GA, Burger MR, Coull BA, et al. Ambient air pollution and the risk of acute ischemic stroke. Arch Intern Med 2012;172:229-34.

25. Xie W, Li G, Zhao D, et al. Relationship between fine particulate air pollution and ischaemic heart disease morbidity and mortality. Heart 2015;101:257-63.

26. Guo L, Li B, Miao JJ, et al. Seasonal variation in air particulate matter (PM10) exposure-induced ischemia-like injuries in the rat brain. Chem Res Toxicol 2015;28:431-9.

27. Kettunen J, Lanki T, Tiittanen P, et al. Associations of fine and ultrafine particulate air pollution with stroke mortality in an area of low air pollution levels. Stroke 2007;38:918-22.

28. Wang Y, Eliot MN, Wellenius GA. Short-term changes in ambient particulate matter and risk of stroke: a systematic review and metaanalysis. J Am Heart Assoc 2014;3:e000983-7.

29. Yorifuji T, Kashima S. Associations of particulate matter with stroke mortality: a multicity study in Japan. J Occup Environ Med 2013;55:768-71.

30. Hart JE, Puett RC, Rexrode KM, et al. Effect Modification of LongTerm Air Pollution Exposures and the Risk of Incident Cardiovascular Disease in US Women. J Am Heart Assoc 2015;4:e002301.

31. Qiu H, Yu IT, Wang X, et al. Cool and dry weather enhances the effects of air pollution on emergency IHD hospital admissions. Int $J$ Cardiol 2013;168:500-5.

32. Zhu N, Li H, Han M, et al. Environmental nitrogen dioxide $\left(\mathrm{NO}_{2}\right)$ exposure influences development and progression of ischemic stroke. Toxicol Lett 2012;214:120-30.

33. Andersen ZJ, Kristiansen LC, Andersen KK, et al. Stroke and longterm exposure to outdoor air pollution from nitrogen dioxide: a cohort study. Stroke 2012;43:320-5.

34. Dijkema MBA, van Strien RT, van der Zee SC, et al. Spatial variation in nitrogen dioxide concentrations and cardiopulmonary hospital admissions. Environ Res 2016;151:721-7.

35. Liu H, Tian $\mathrm{Y}, \mathrm{Xu} \mathrm{Y}$, et al. Association between ambient air pollution and hospitalization for ischemic and hemorrhagic stroke in China: A multicity case-crossover study. Environ Pollut 2017;230:234-41.

36. Chen R, Zhang Y, Yang C, et al. Acute effect of ambient air pollution on stroke mortality in the China air pollution and health effects study. Stroke 2013;44:954-60.

37. Qian Y, Zhu M, Cai B, et al. Epidemiological evidence on association between ambient air pollution and stroke mortality. J Epidemiol Community Health 2013;67:635-40.

38. Cordonnier C, Sprigg N, Sandset EC, et al. Stroke in women - from evidence to inequalities. Nat Rev Neurol 2017;13:521-32.

39. Sang N, Yun Y, Li H, et al. SO2 inhalation contributes to the development and progression of ischemic stroke in the brain. Toxicol Sci 2010;114:226-36.

40. Shah AS, Lee KK, McAllister DA, et al. Short term exposure to air pollution and stroke: systematic review and meta-analysis. BMJ 2015;350:h1295.

41. Huang F, Luo Y, Tan P, et al. Gaseous Air Pollution and the Risk for Stroke Admissions: A Case-Crossover Study in Beijing, China. Int J Environ Res Public Health 2017;14:189.

42. Zanobetti A, Schwartz J, Gold D. Are there sensitive subgroups for the effects of airborne particles? Environ Health Perspect 2000;108:841-5. 